\title{
Damage-control evaluation of high-strength steel frames with energy dissipation bays
}

$1 \mathrm{Ke} \mathrm{Ke} \mathrm{BSC,PhD}$

Former PhD candidate, State Key Laboratory of Disaster Reduction in

Civil Engineering, Tongji University, Shanghai, China; Assistant Professor, College of Civil Engineering, Hunan University, Changsha, China; Postdoctoral Fellow, Department of Building and Real Estate, The Hong Kong Polytechnic University, Hung Hom, Kowloon, Hong Kong, China

2 Yiyi Chen MSc, PhD

Professor, State Key Laboratory of Disaster Reduction in Civil

Engineering, Tongji University, Shanghai, China
$3 \quad$ Liang-Jiu Jia MSc, PhD

Assistant Professor, Research Institute of Structural Engineering and Disaster Reduction, Tongji University, Shanghai, China (corresponding author: Ij_jia@tongji.edu.cn)
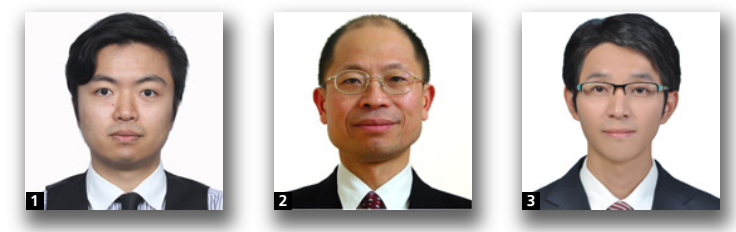

This paper reports on a practical seismic-damage-control evaluation method of a high-strength steel (HSS) system comprising HSS frames with energy dissipation bays (EDBs). First, the design concept and seismic performance of the system are illustrated and verified by an experiment on a large-scale two-storey two-bay HSS frame with EDBs. Critical issues considering quantification of the seismic-damage-control threshold and the performance requirement of HSS members are clarified. A stepwise procedure that accounts for both the peak response of the HSS members and the cumulative effect of EDBs is then constructed by applying the energy balance concept and a micromechanicsbased fracture model. Subsequently, the procedure is implemented on a prototype structure. The results indicate that the proposed procedure is effective for evaluating seismic performance of both HSS members and EDBs. Compared with direct application of non-linear history response analysis, which is time consuming, the proposed procedure simultaneously retains conceptual and computational advantages.

\section{Notation}

$D_{\text {ini }}$

damage index quantifying the limit state of energy dissipation bays (EDBs)

$D_{\text {prop }}$

$\mathrm{d} D_{\text {ini }}$

$\mathrm{d} \varepsilon_{\mathrm{eq}}^{\mathrm{p}}$

$E_{\text {a }}$

$E_{\mathrm{e}}$

$E_{\mathrm{h}}$

$E_{\mathrm{p}}$

$G$

$G_{\mathrm{c}}$

$M$

$M_{1}^{*}$

$m$

$S$

$S_{\mathrm{V}}$

$T$

$T_{1}$

$V_{\mathrm{b}}$

$V_{\mathrm{e}}$

$V_{\text {yEDB }}$

crack propagation index

incremental crack initiation index

incremental equivalent plastic strain

nominal absorbed energy

nominal elastic energy

hysteretic plastic energy

nominal plastic energy

current absorbed energy of a unit area since the instant of fracture initiation

threshold value for absorbed energy of a unit area moment of members

effective mass of fundamental mode

mass vector

lateral load distribution vector

pseudo-velocity

stress triaxiality

fundamental period

base shear corresponding to the target roof displacement

base shear corresponding to the elastic system base shear corresponding to yield of EDBs
$V_{\text {yEDB }}^{\prime} \quad$ yield strength of the SDOF system

$\alpha$

$\Gamma_{1}$

$\gamma$

$\delta$

$\delta^{\prime}$

$\delta_{\mathrm{e}} \quad$ maximum roof displacement of the corresponding elastic structural system

$\delta_{\mathrm{e}}^{\prime} \quad$ maximum displacement of the equivalent elastic SDOF system

$\delta_{\mathrm{yEDB}} \quad$ equivalent yield roof displacement of EDB

$\delta_{\mathrm{yEDB}}^{\prime} \quad$ yield displacement of the equivalent SDOF system

$\delta_{\mathrm{yHSS}} \quad$ yield roof displacement of the HSS members

$\zeta \quad$ sequence factor

$\zeta_{\mathrm{T}} \quad$ threshold of the sequence factor

$\mu \mathrm{a} \quad$ accumulated ductility

$\sigma_{\mathrm{e}} \quad$ effective stress

$\phi_{1}$ modal vector of the fundamental vibration mode

$\phi_{\mathrm{r}} \quad$ roof element of the modal vector corresponding to the fundamental mode

$\chi_{\mathrm{cr}} \quad$ material parameter for the damage index

$\psi \quad$ damage-control factor 


\section{Introduction}

In order to expand the application of high-strength steel (HSS) (Bjorhovde, 2004; Miki et al., 2002) in seismic regions, HSS structures implemented with energy dissipation members of mild carbon or low-yield steels have been proposed. Although the ductility of HSS members (Ellobody, 2012; Green et al., 2002; Sause and Fahnestock, 2001) is generally not as satisfactory as those of mild carbon or low-yield steels, their excellent elastic performance and limited ductility are still usable for seismic-resistant structures. Furthermore, compared with some innovative seismic-resistant structures (Chey et al., 2015; Fang et al., 2014) that might be challenging due to the relatively complicated field construction efforts or more significant cost, HSS structures with energy dissipation members retain constructional and economic efficiency. Extensive research works considering HSS structures with energy dissipation members have thus been carried out. For instance, Wada et al. (1992) proposed damage-tolerant structures in which HSS members were expected to stay elastic under ground motions. Dual-steel structures involving HSS members have also been investigated (Dubina et al., 2008; Ke and Chen, 2016; Tenchini et al., 2014). These works indicated that when combining HSS members with energy dissipation members rationally, the system showed excellent seismic performance and inelastic deformation could be restricted to the energy dissipation members, thus achieving damage-control behaviour (Wada et al., 1992). A fundamental issue for the application of these systems thus lies in the rational arrangement of HSS members to ensure that inelastic deformation is restricted to the energy dissipation members under expected earthquakes. However, as the combination of HSS members and energy dissipation members would generally lead to a variation of the hysteretic feature, applicability of current inelastic evaluation procedures (Kalkan and Kunnath, 2007; Lagaros and Fragiadakis, 2011) or empirical design equations (Chopra and Chintanapakdee, 2004; Hatzigeorgiou and Beskos, 2009) established on bilinear models with negligible post-yielding stiffness becomes questionable. In addition, since energy dissipation members are designated as the primary source of plastic energy dissipation and are expected to experience significant cumulative damage, they face the risk of fracture under a strong earthquake event. Therefore, cracking potential of energy dissipation members in these systems should also be critically assessed.

In this paper, a seismic evaluation procedure is established, with a focus on the damage-control behaviour of a proposed HSS structure (HSSs frame with energy dissipation bays $($ EDBs $)$ ). The design concept of the system is firstly illustrated. The rationality of the proposed system is then verified by means of a large-scale test. The test programme and the results are briefly described. Recognising that improper design might expose a structure to the risk of significant inelastic deformation development in HSS members or fracture due to excessive cumulative damage in EDBs, both the peak response and the cumulative response of the structure should be involved in an evaluation procedure. To facilitate design and assessment, computational efficiency is also expected. Therefore, a stepwise evaluation procedure was established in this research. In this procedure, the performance of HSS members is assessed by a spectral method motivated by the energy balance concept, and the cracking behaviour of the EDBs is evaluated by a proposed fracture model. The procedure is applied to a preliminarily designed prototype structure for demonstration. To validate the accuracy of the procedure in identifying damage to HSS members, the predictions determined from the proposed procedure are compared with results extracted from non-linear response history analysis (NL-RHA) utilising the simplified structural model.

\section{Design concept and test programme of HSS frames with EDBs}

\subsection{Design concept}

Unlike a conventional steel moment-resisting frame (SMRF), the proposed system is realised by combining HSS members and energy dissipation beams of mild carbon steel, as illustrated in Figure 1(a). Hence, an EDB is constructed in a preselected bay. As the motive is to make the EDB dissipate energy, it is designed to possess a larger stiffness and smaller yield drift. Correspondingly, the remaining bays, composed of HSS members, are expected to be free of damage in a certain deformation range. Since the HSS has a larger yield stress, the elastic deformation capacity of a moment-resisting frame can be enhanced considerably. Accordingly, the early yielding of the EDB and the elastic behaviour of the HSS frame members lead to favourable damage-control behaviour, and a 'damage-control stage' is achieved (Figure 1(b)). In the 'main structural damage stage', in which the HSS members develop inelastic deformation, ductile behaviour can also be achieved owing to the energy dissipation capacity of the HSS members. Figure 1(b) shows a typical load-displacement curve of the proposed system. Compared with a conventional SMRF, which can be idealised as an elasto-plastic system with negligible post-yielding stiffness, the proposed system shows distinct post-yielding stiffness in the damage-control stage, and a bilinear kinematic hysteretic model can be used to describe the structural non-linearity, as shown in Figure 1(c). The hysteretic curve then forms a damage-control core (DCC).

In practice, even if the HSS frame is designed with the same sections as a conventional SMRF structure, the yield drift can be significant (around $1 \cdot 5-2 \%$ for HSS with a yield stress of $460 \mathrm{MPa}$ ). In contrast, for a conventional SMRF, the yield drift is generally around $1 \%$, and its increase inevitably involves heavy sections. To illustrate the attractiveness of the proposed system, two example structures are presented and compared in Figure 2. These systems meet the requirement of the Chinese seismic code (CMC, 2010). The design basic 


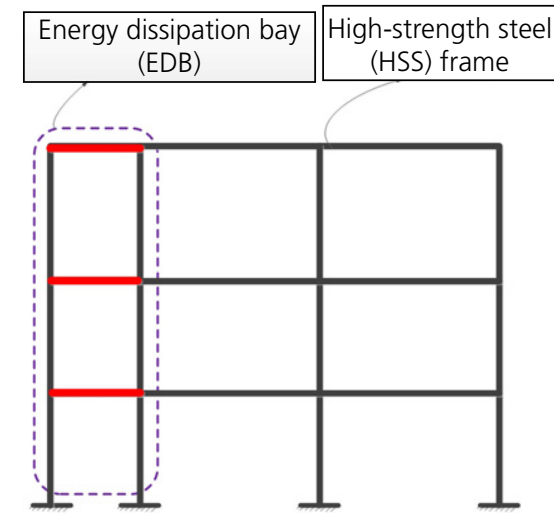

(a)

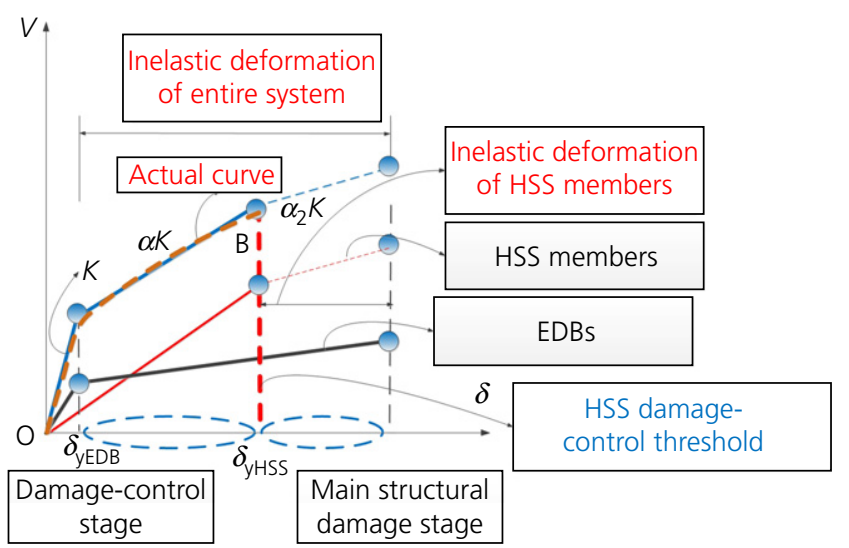

(b)

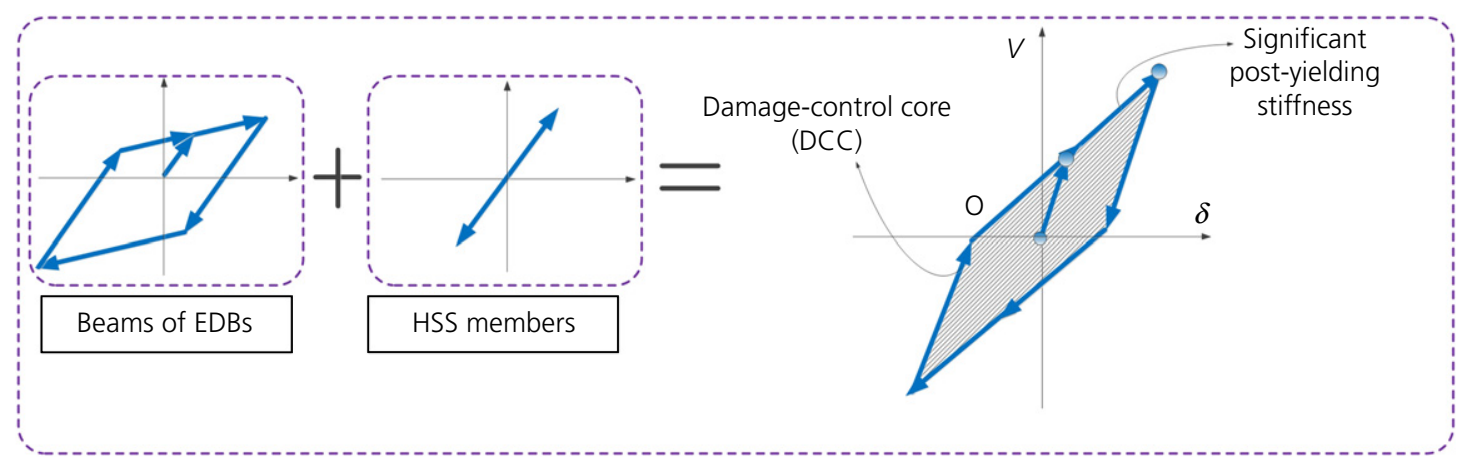

(c)

Figure 1. Design concept of HSS frames with EDBs: (a) design concept; (b) non-linear feature; (c) DCC in the damage-control stage

acceleration is $0.4 \mathrm{~g}$. A dead load of $4.8 \mathrm{kN} / \mathrm{m}^{2}$ and a live load of $2 \mathrm{kN} / \mathrm{m}^{2}$ are assumed. Frame A is representative of a conventional SMRF and all members are designed with a yield stress of $235 \mathrm{MPa}$. Frame B is a typical representative of the proposed system. Apart from the beams of the EDBs, which are designed with steel with a yield stress of $235 \mathrm{MPa}$, the remaining bays are designed with HSS of $460 \mathrm{MPa}$. Nonlinear structural models were then established, considering a stress hardening ratio of $2 \%$.
The pushover-unloading curves (push to a roof drift of $3 \%$ ) of frames $\mathrm{A}$ and $\mathrm{B}$ considering the fundamental vibration mode are illustrated in Figure 2. As a conventional SMRF system, frame A develops entire yielding after the roof drift reaches about $1 \%$, followed by negligible post-yielding stiffness. In contrast, the damage-control behaviour of frame $\mathrm{B}$ results in favourable significant post-yielding stiffness up to a roof drift of approximately $1 \cdot 5 \%$. More importantly, the clear enhancement of frame $\mathrm{B}$ does not involve heavier sections since the 

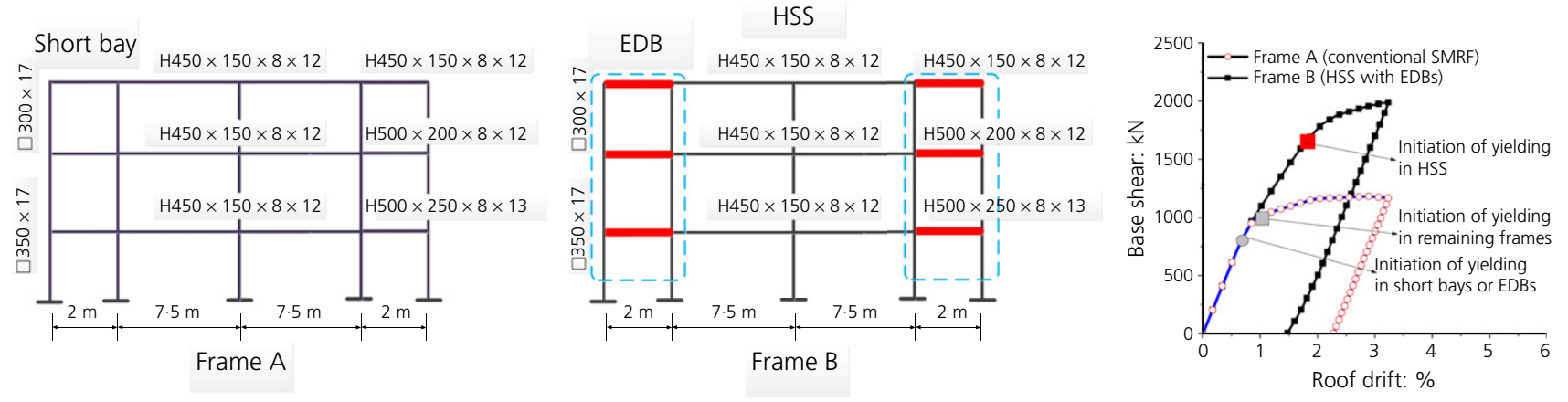

Figure 2. Comparison of a conventional SMRF (frame A) and the proposed system (frame B). $\square$, box section

weight and elastic stiffness of the structure are the same as frame A. In this context, the seismic demand of ground motions will not increase.

\subsection{Test programme}

To verify the seismic performance of the proposed structure, a large-scale welded frame with two storeys and two bays was designed and tested under cyclic loading. A preselected bay installed with energy dissipation beams of mild carbon steel is designated as the EDB and the remaining frames are constructed from HSS members with a yield stress larger than $460 \mathrm{MPa}$. Details of the experiment are given in Figure 3. During the experiment, a vertical load of $1500 \mathrm{kN}$, simulating the gravity load, was first applied and distributed to all the columns. The cyclic loads were then involved. To simulate the actual seismic action closely, lateral triangle loads (the ratio of the horizontal loads was 1:2) were applied. The loading protocol was modified based on AISC 341-10 (AISC, 2010a) by inserting the amplitudes of $0 \cdot 2 \%, 1 \cdot 25 \%$ and $1 \cdot 75 \%$.

The storey shear force versus storey drift curves considering the entire loading cycle and the DCC (maximum storey drift of $2 \%$ ) are given in Figures 4(a) and 4(b), respectively. The model curve following the bilinear kinematic law is also presented. Before the HSS members developed significant inelastic deformation, there is satisfactory agreement between the bilinear model with significant post-yielding stiffness and the experimental curve. As a representative result, the moment distributions of structural members (members surrounding joint $B$ in Figure 3) derived from strain data and damage phenomena at various load amplitudes are shown in Figure 5. In general, combination of HSS members and the EDB leads to a favourable damage evolution mode. After the EDB yielded at a drift of $0.5 \%$, it began to dissipate plastic energy stably. With an increase in drift, slight local buckling was firstly detected in the beams of the EDB when the drift reached $1 \%$. At this drift, the HSS members remained totally elastic. After the drift increased to $1 \cdot 5 \%$, the inelastic deformation of the HSS members was insignificant. This is supported by the globally elastic behaviour illustrated in Figure 5. Therefore, the damage-control behaviour was achieved. After the drift reached 3\%, all members developed plastic deformation. At this drift, visible fractures in the EDB were observed. However, the HSS members still exhibited ductile behaviour without failure.

\section{A damage-control seismic evaluation procedure of HSS frames with EDBs}

\subsection{Quantification of structural non-linearity}

To quantify the structural non-linearity of the damage-control stage, a sequence factor is defined as

1. $\zeta=\frac{\delta}{\delta_{\mathrm{yEDB}}}$

where $\delta$ is the target roof displacement and $\delta_{\mathrm{yEDB}}$ is the roof displacement equivalent to yielding of the EDB, which can be solved by idealising the actual curve with a bilinear curve (Figure 1(b)). Note that the definition of this parameter can feature the yielding sequence of the entire system. In particular, a bilinear simplification is applied to the pushover curve in the damage-control stage, utilising two tangent lines going through the origin $\mathrm{O}$ and the point $\mathrm{B}$ in Figure 1(b) corresponding to the inception of yielding in the HSS frame. To ensure that the HSS frame is strictly damage-free, point B is determined by the first yield point in the HSS members. Thus, $\delta_{\mathrm{yEDB}}$ is obtained from the intersection point of the two tangent lines. Correspondingly, the post-yielding stiffness ratio $(\alpha)$, defined as the ratio of the post-yielding stiffness to the initial stiffness (Figure 1(b)), is obtained. An equivalent target sequence factor denoting the HSS damage-control threshold is determined from

2. $\zeta_{\mathrm{T}}=\frac{\delta_{\mathrm{yHSS}}}{\delta_{\mathrm{yEDB}}}$ 
Structures and Buildings

Volume 170 Issue SB9
Damage-control evaluation of

high-strength steel frames with energy

dissipation bays

Ke, Chen and Jia

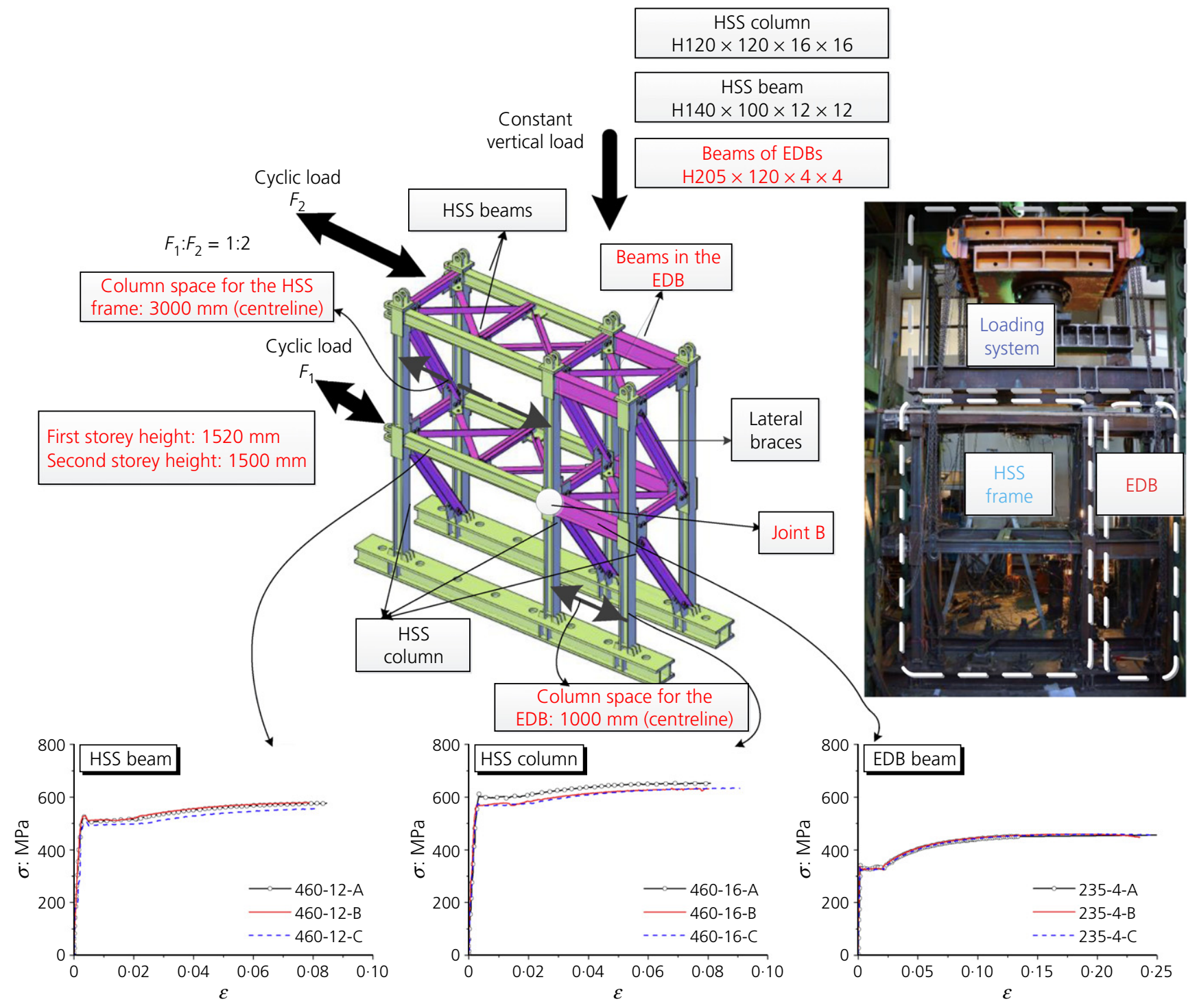

Figure 3. Specimen details and test setup of the HSS frame with EDB

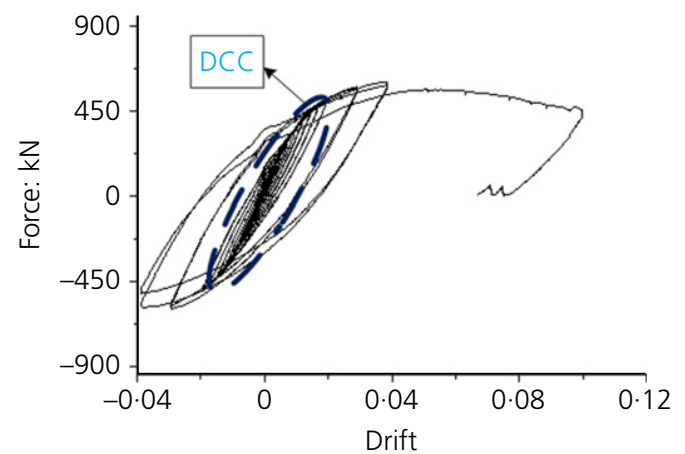

(a)

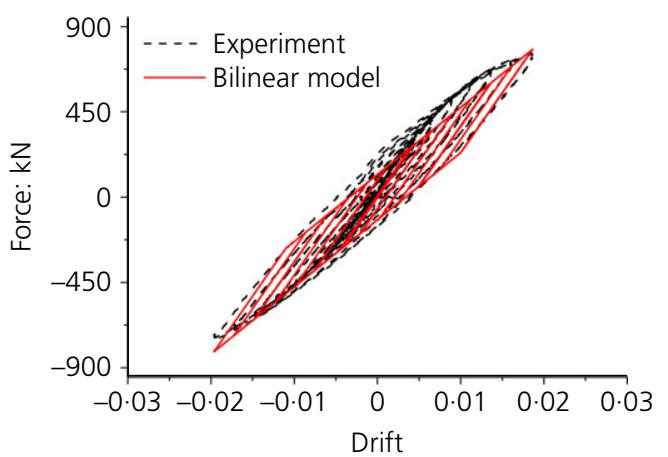

(b)

Figure 4. Hysteretic curves: (a) considering entire loading cycle; (b) DCC 

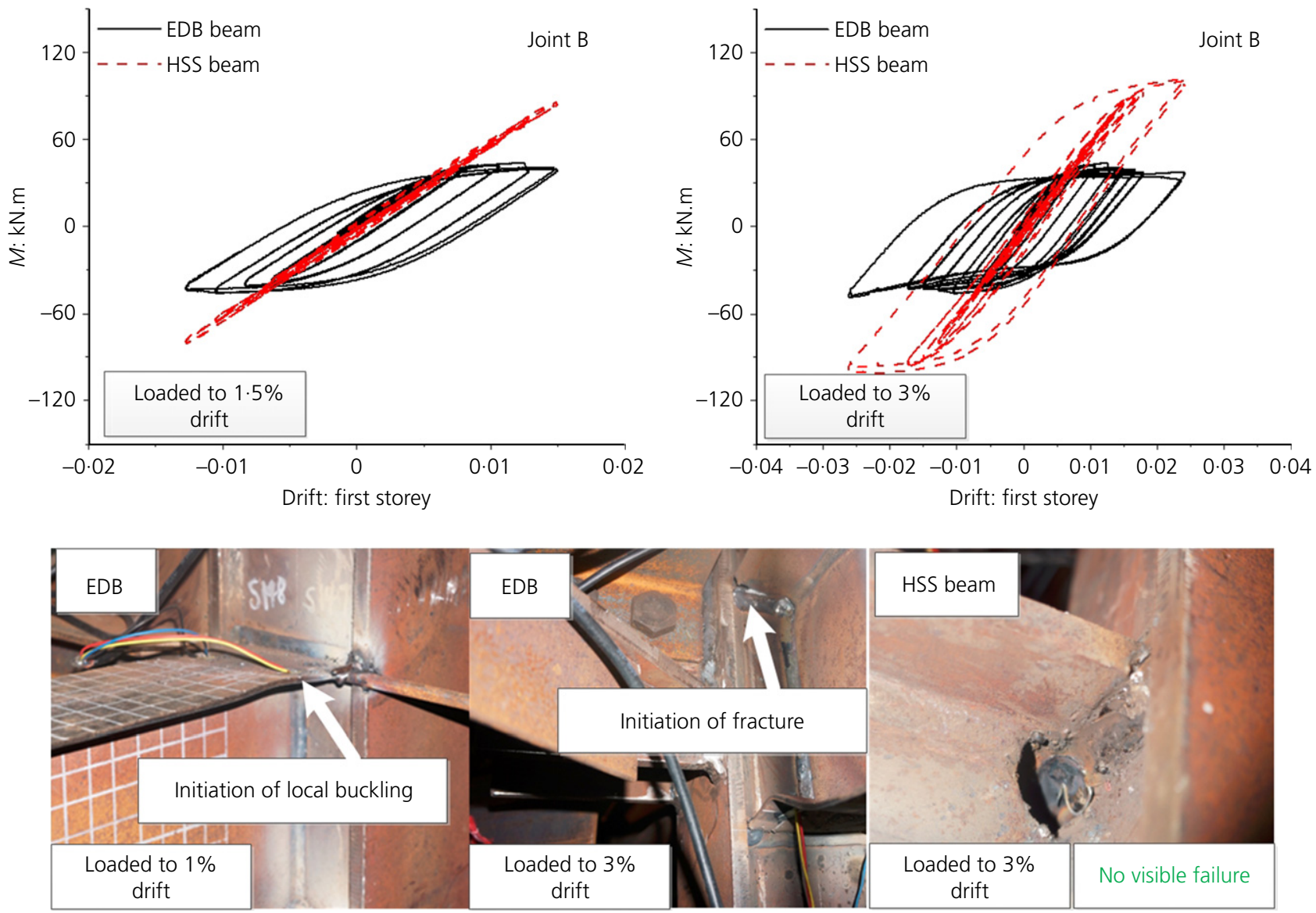

Figure 5. Damage-control behaviour reflected by members' internal moment distribution and the damage evolution at various loading drifts

where $\delta_{\text {yHSS }}$ is the yield roof displacement of the HSS members, corresponding to the HSS damage-control threshold. When the displacement is below this threshold, the HSS members are guaranteed to be damage-free.

\subsection{Critical issues of damage-control behaviour and performance requirements}

In general, the core of damage-control behaviour is the restriction of damage in EDBs under expected earthquakes. Thus, one method is to increase the gap between the yield drift of the HSS frames and the EDBs, which could facilitate restraining damage within the EDBs. However, even though this was considered during the specimen design, with the yield drift gap between the EDBs and the HSS frames intentionally enlarged, fracture of the EDBs occurred. This was due to the fact that significant damage was concentrated in the EDBs. In this regard, to achieve damage-control behaviour, both the HSS frames and the EDBs should be considered. This necessity can be further highlighted by the following examples. Single-degreeof-freedom (SDOF) systems following the bilinear hysteretic law with significant post-yielding stiffness verified by the experimental research are adopted here for clarification. In particular, a series of SDOF systems with different DCC shapes (by varying $\alpha$ and $\zeta$ ) is analysed under a ground motion (LA01, Imperial Valley, 19 May 1940, El Centro). The weight of the SDOF system is assumed to be $1000 \mathrm{kN}$. The results in terms of accumulated ductility (Nakashima et al., 1996) given by Equation 3 and denoting the cumulative inelastic deformation demand of the structural members are presented in Figure 6.

$$
\text { 3. } \mu \mathrm{a}=\frac{E_{\mathrm{h}}}{(1-\alpha) \delta_{\mathrm{yEDB}}^{\prime} V_{\mathrm{yEDB}}^{\prime}}
$$

where $E_{\mathrm{h}}$ denotes the cumulative hysteretic energy dissipation and $V_{\mathrm{yEDB}}^{\prime}$ and $\delta_{\mathrm{yEDB}}^{\prime}$ are, respectively, the yield strength and yield displacement of the SDOF system, corresponding to the yielding of EDBs in a structural system. For comparison, the result of perfectly elasto-plastic systems $(\alpha=0)$ representing conventional SMRF systems is also shown in the figure. It can be seen that an increase in the post-yielding stiffness ratio and the sequence factor both result in significant cumulative inelastic deformation demand, irrespective of the structural period $\left(T_{1}\right)$. For the proposed system, since the accumulated ductility is expected to be experienced by the EDBs only in the 


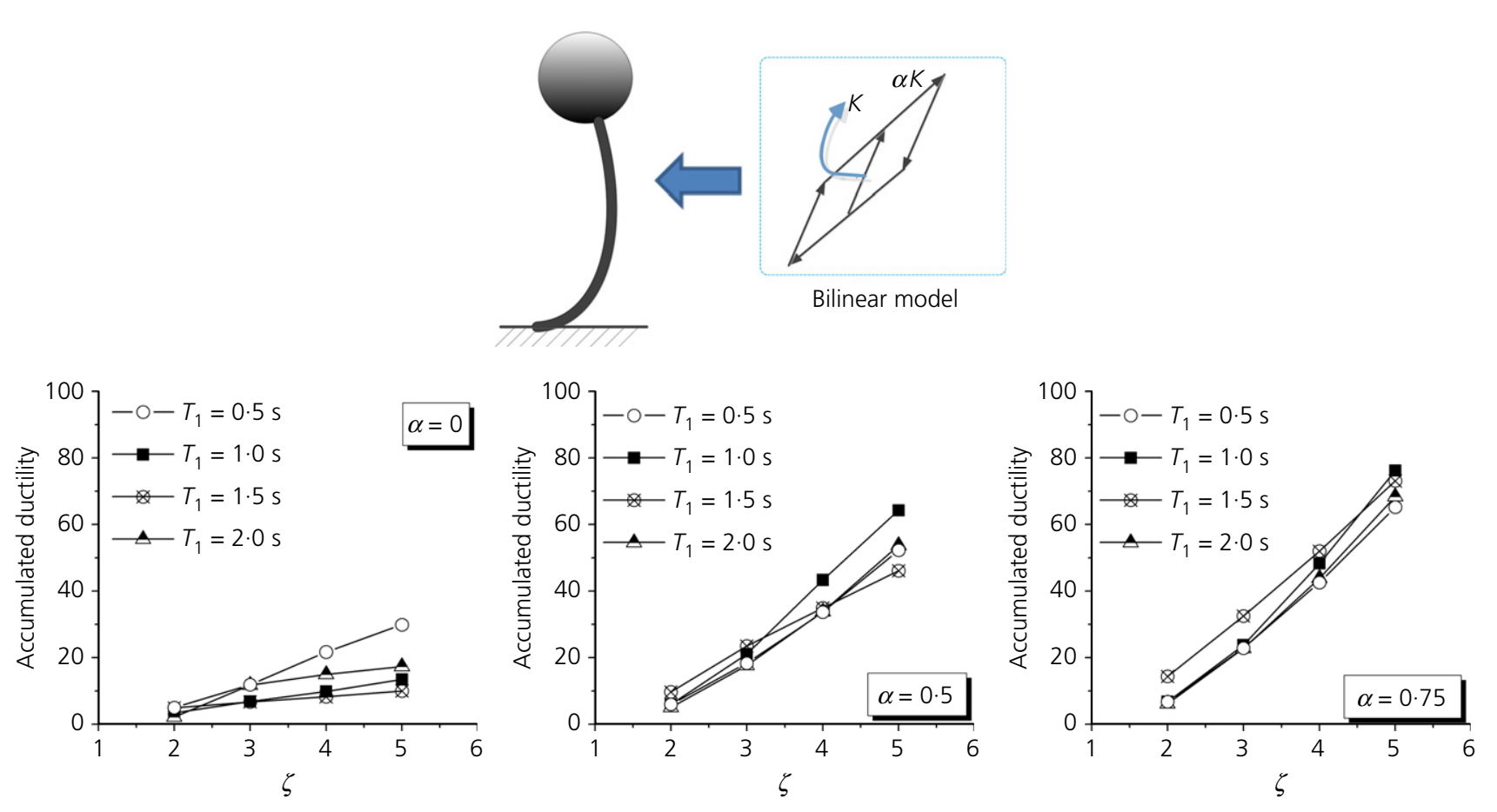

Figure 6. Accumulated ductility of SDOF systems of different DCC shapes

damage-control stage, a DCC of significant post-yielding stiffness ratio and sequence factor will likely expose the EDBs to the potential of failure.

In light of the above discussion, it can be seen that, although damage to HSS frames can be prevented by enlarging $\zeta_{\mathrm{T}}$ and strengthening the HSS frame, the significant inelastic deformation introduced into the EDBs still needs to be considered. In this regard, the rational combination of HSS members and EDBs is a most critical issue for practical applications. Therefore, it is essential to explicitly account for the rational design of HSS members and their proper combination with EDBs. In particular, the performance requirements considering the damage-control stage are as follows.

- The HSS members should stay elastic under expected ground motions.

When the HSS members stay elastic, the EDBs should provide a stable source of energy dissipation without the occurrence of fracture.

However, it is noted that these requirements are for the damage-control stage. For a system entering the main structural damage stage, the requirements will be dependent on specific design motives.

\subsection{Quantification of the performance requirement}

\subsubsection{HSS member performance evaluation}

According to the performance requirements, a critical issue to be solved is assessing the performance of HSS members under expected ground motions. The modified energy balance concept is adopted here ( $\mathrm{Ke}$ and Chen, 2014; Leelataviwat et al., 2009; Sahoo and Chao, 2010; Wongpakdee et al., 2014). The energy balance equation (Leelataviwat et al., 2009) can be firstly applied, which is given by

4. $\quad \gamma\left(\frac{1}{2} M_{1}^{*} S_{\mathrm{v}}^{2}\right)=E_{\mathrm{e}}+E_{\mathrm{p}}$

where $\gamma, M_{1}^{*}$ and $S_{\mathrm{v}}$ are the energy factor, the effective mass of the fundamental mode and the pseudo-velocity considering the fundamental vibration mode, respectively. The energy factor is defined as the ratio of the energy absorbed by an inelastic system to that of a corresponding elastic system under monotonic loading. $E_{\mathrm{e}}$ is the nominal elastic energy and $E_{\mathrm{p}}$ is the nominal plastic energy. Summation of $E_{\mathrm{e}}$ and $E_{\mathrm{p}}$ leads to nominal absorbed energy $E_{\mathrm{a}}$, which is determined by the shaded area of the skeleton load-displacement curve with a target displacement (Figure 7(a)). Therefore, the result of the left-hand side of Equation 4 can be defined as the nominal energy demand and the right-hand side leads to the nominal energy capacity.

Based on the assumption that the system is dominated by the fundamental mode and the premise that the HSS members remain elastic, Equation 4 can be extended to structural systems using an equivalent SDOF system (Leelataviwat et al., 2009). For a system satisfying damage-control behaviour reflected by the significant post-yielding stiffness provided by 


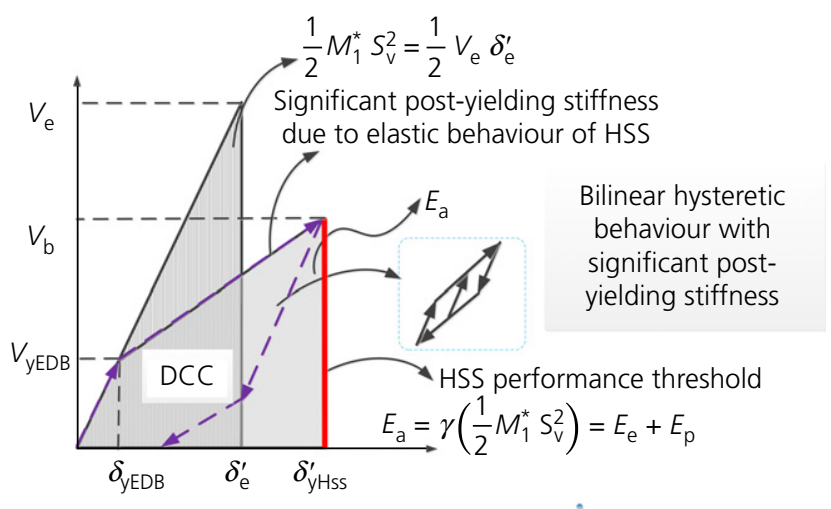

(a)

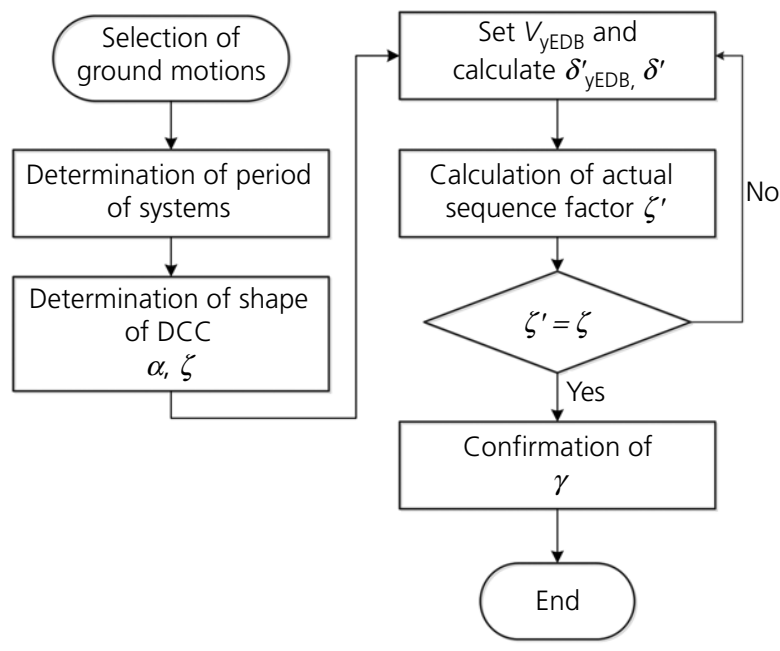

(b)

Figure 7. Energy balance of HSS frame with EDBs in the damage-control stage (equivalent SDOF system): (a) the energy balance and the energy factor; (b) flow chart for computation of the energy factor

HSS members (Figure 7(a)), $\gamma$ can be solved as

5.

$$
\begin{aligned}
\gamma & =\frac{E_{\mathrm{e}}+E_{\mathrm{p}}}{(1 / 2) M_{1}^{*} S_{\mathrm{v}}^{2}} \\
& =\frac{(1 / 2) V_{\mathrm{yEDB}} \delta^{\prime}{ }_{\mathrm{yEDB}}+(1 / 2)\left(V_{\mathrm{yEDB}}+V_{\mathrm{b}}\right)\left(\delta^{\prime}-\delta^{\prime}{ }_{\mathrm{yEDB}}\right)}{(1 / 2) V_{\mathrm{e}} \delta^{\prime}{ }_{\mathrm{e}}}
\end{aligned}
$$

where $V_{\mathrm{yEDB}}, V_{\mathrm{b}}$ and $V_{\mathrm{e}}$ are, respectively, the base shear corresponding to yielding of the EDBs, the base shear corresponding to the target roof displacement and the base shear of the corresponding elastic system. It is noted that $V_{\mathrm{yEDB}}, V_{\mathrm{b}}$ and $V_{\mathrm{e}}$ of the equivalent SDOF system are identical to the base shear of the structural system (Leelataviwat et al., 2009), and $\delta_{\text {yEDB }}^{\prime}$, $\delta^{\prime}$ and $\delta_{\text {e }}^{\prime}$ of the equivalent SDOF system, which can be associated with structural features, are determined as follows.

6. $\delta_{\mathrm{yEDB}}^{\prime}=\frac{\delta_{\mathrm{yEDB}}}{\Gamma_{1} \phi_{\mathrm{r}}}$
7. $\delta^{\prime}=\frac{\delta}{\Gamma_{1} \phi_{\mathrm{r}}}$

8. $\delta_{\mathrm{e}}^{\prime}=\frac{\delta_{\mathrm{e}}}{\Gamma_{1} \phi_{\mathrm{r}}}$

where $\Gamma_{1}, \phi_{\mathrm{r}}$ and $\delta_{\mathrm{e}}$ are, respectively, the participation factor of the fundamental mode, the roof element of the modal vector corresponding to the fundamental mode and the maximum roof displacement of the corresponding elastic system. Therefore, with application of the equivalent SDOF system, the energy factor for HSS frames with EDBs can be determined from

9. $\gamma=\psi\left[2 \zeta-1+\alpha(\zeta-1)^{2}\right]$

10. $\psi=\left(\frac{V_{\mathrm{yEDB}}}{V_{\mathrm{e}}}\right)^{2}$

where $\psi$ is defined as the damage-control factor. Computation of the energy factor $\gamma$ can be solved by an iteration approach following the flow chart in Figure 7(b). Therefore, the performance of HSS members can be evaluated by performing a pushover analysis. Specifically, the lateral load corresponding to the fundamental vibration mode, determined by Equation 11, is applied to the structure.

\section{1. $S=\boldsymbol{m} \phi_{1}$}

where $\boldsymbol{S}$ is the lateral load distribution vector, $\boldsymbol{m}$ is the mass vector and $\phi_{1}$ is the modal vector of the fundamental vibration mode. Then, the non-linearity features $\left(\alpha, \zeta\right.$ and $\left.\zeta_{\mathrm{T}}\right)$ quantifying the shape of the DCC and HSS members' damage-control threshold can be determined based on the pushover curve utilising Equation 11. Therefore, the nominal energy demand diagram (Figure 8) can be constructed from Equations 4 and 9 by applying the sequence factor as the horizontal coordinate. Meanwhile, the energy capacity diagram in terms of the absorbed energy versus the sequence factor can also be obtained with the pushover curve, and the vertical coordinate can be determined by computing the work done by the lateral loads. Subsequently, a performance evaluation of the HSS members can be carried out with the constructed diagrams. When an intersection point of the demand curve and capacity curve is placed before the damage-control threshold, the nominal energy balance can be achieved before HSS members are damaged. Otherwise, occurrence of damage in HSS members is expected. 


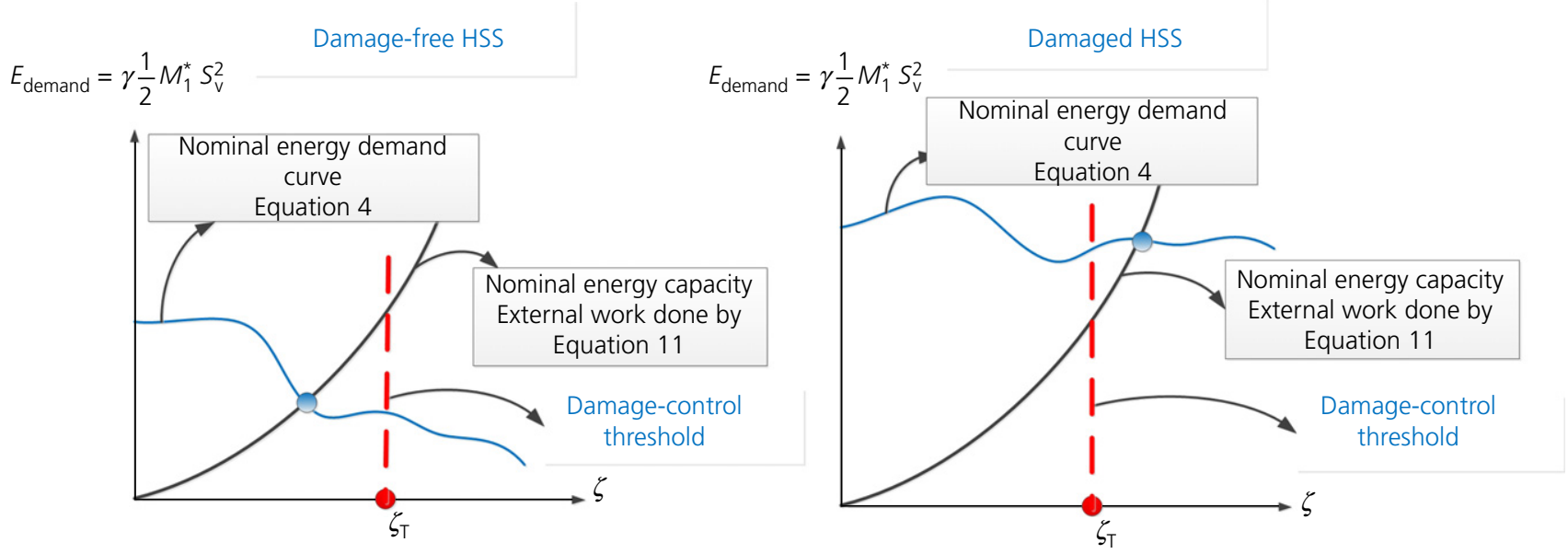

Figure 8. Performance evaluation of HSS members based on energy balance concept

\subsubsection{Performance evaluation of EDBs based on micromechanics-based fracture model}

In this research, to precisely account for the potential fracture of EDBs, a micromechanics-based ductile fracture model (Jia et al., 2016) is adopted. Since the failure of beams in the EDB is typical ductile fracture under cyclic large-strain loading, the validated fracture model is applicable. Specifically, a damage index (Jia and Kuwamura, 2014, 2015), quantifying the crack initiation in a small increment, is given by

12.

$$
\mathrm{d} D_{\text {ini }}=\left\{\begin{array}{cc}
\frac{\mathrm{d} \varepsilon_{\mathrm{eq}}^{\mathrm{p}}}{\chi_{\mathrm{cr}} \cdot \mathrm{e}^{-(3 / 2) T}} & T \geq-\frac{1}{3} \\
0 & T<-\frac{1}{3}
\end{array}\right.
$$

where $\chi_{\mathrm{cr}}$ is a material parameter, $\mathrm{d} \varepsilon_{\mathrm{eq}}^{\mathrm{p}}$ is the incremental equivalent plastic strain and $T$ is the stress triaxiality, defined by the ratio of the hydrostatic pressure to the equivalent Mises stress for metals. Ductile fracture initiation is postulated to occur when $D_{\text {ini }}$ reaches 1 . Thus, the damage index $\left(D_{\text {ini }}\right)$ corresponding to the crack initiation is used to quantify the limit state of EDBs, given by

\section{3. $D_{\text {ini }}=\sum\left(\mathrm{d} D_{\text {ini }}\right)$}

In the fracture model, a crack propagation rule is also employed using an energy approach (Jia et al., 2016), where the corresponding crack propagation index $D_{\text {prop }}$ is given by

14. $D_{\text {prop }}=\frac{G}{G_{\mathrm{c}}}$ where $G$ is the current absorbed energy of a unit area since the instant of fracture initiation and $G_{\mathrm{c}}$ is the threshold value for absorbed energy of a unit area. $G_{\mathrm{c}}$ can be obtained based on Charpy impact tests (Jia et al., 2016). Material deterioration is also considered by using the concept of effective stress $\left(\sigma_{\mathrm{e}}\right)$, given by

15. $\sigma_{\mathrm{e}}=\left(1-D_{\text {prop }}\right) \sigma$

To validate accuracy of the model for predicting ductile fracture of the EDB, a finite-element analysis (FEA) shell model was established using Abaqus. All members of the test frame were modelled with three-dimensional shell elements (S4R) based on the measured dimensions. Since out-of-plane braces were angle members that were relatively rigid in the axial direction, the 'MPC pin' simplification that idealises the braces with rigid truss elements was adopted. The procedure for the application of loads was the same as that in the experiments: the axial forces derived from the strain readings were first applied to the each column and kept constant during the whole simulation. Initial imperfections are considered in the model. Since this quantity was not precisely measured in the test programme, the magnitude of initial imperfections was determined by a trial-and-error procedure based on the buckling shape of the beams in the EDB. Eventually, a magnitude of $h / 500$, considering buckling shapes identical to the specimen, was adopted for all the beams in the EDB. The fracture model was implemented in the material property and only assigned to beams in the EDB. To completely reflect the damage evolution, the crack initiation, crack propagation rules and deterioration of stress-carrying capacity were all considered in the EDB, which can be accounted for in the material module of Abaqus. The parameters of fracture properties were calibrated based on coupon test of the material following the 
procedure proposed by Jia et al. (2014). During the modelling, sensitivity of mesh sizing was also studied and it was found that the mesh size had a minor influence on the results. Thus, a mesh size of $4 \mathrm{~mm}$ was adopted in the plastic zone of beams in the EDB and a mesh size of $1 \mathrm{~mm}$ was used in the welding area. As the welding wire and the welding process generally compromise the fracture behaviour of the material, elements in the weld region were considered by setting the fracture parameter as $30 \%$ of the base metal, based on a previous study on ductile fracture of materials in various subzones of a welded joint (Jia et al., 2014), for the purpose of simplification. The crack initiation index $\left(\chi_{\mathrm{cr}}\right)$ was equal to 2.2 and 0.7 for the base metal and the weld, respectively, and the crack propagation index $\left(G_{\mathrm{c}}\right)$ was $1.55 \mathrm{~J} / \mathrm{mm}^{2}$ for the steel Q235B considered in this study.
The numerical and experimental results of the tested HSS frame of the EDB are compared in Figure 9. The results show that the applied fracture model can be used to identify crack initiation and to account for crack propagation with satisfactory accuracy, strongly strengthening its potential in the proposed structure. To provide further understanding of the damage evolution in EDBs, the development of $D_{\text {ini }}$ at the cracking location of spot A is plotted against the base shear force and the drift in Figure 10. It can be seen that when the drift is not significant, $D_{\text {ini }}$ grows slowly with increasing drift, but the growth of $D_{\text {ini }}$ becomes drastic at large drift amplitudes. Even though the specimen was loaded repeatedly with the same peak target drift, a substantial increase in $D_{\text {ini }}$ was observed. This phenomenon exactly supports the findings regarding the SDOF system responses in Section 3.2.
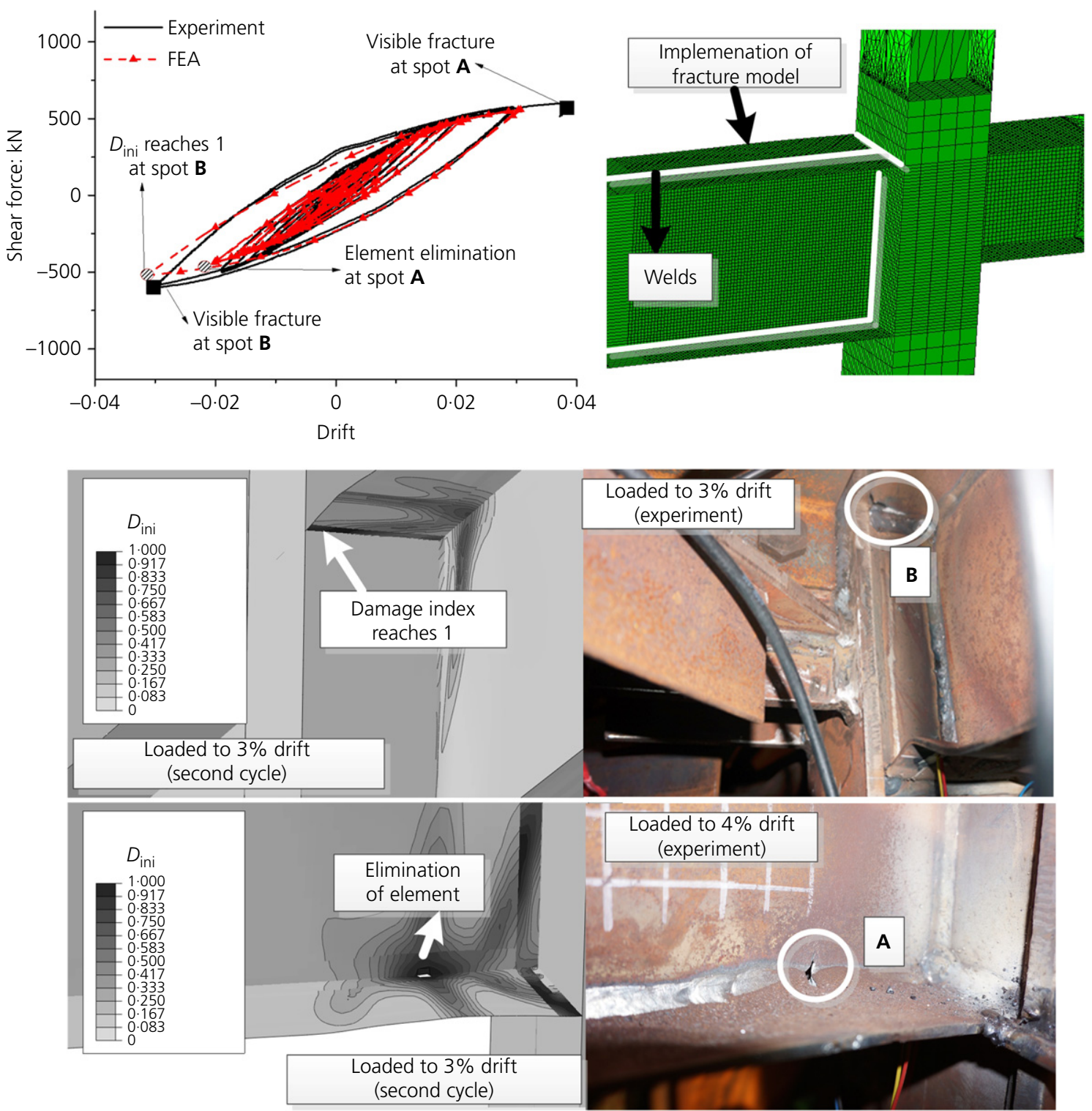

Figure 9. Verification of the fracture model 

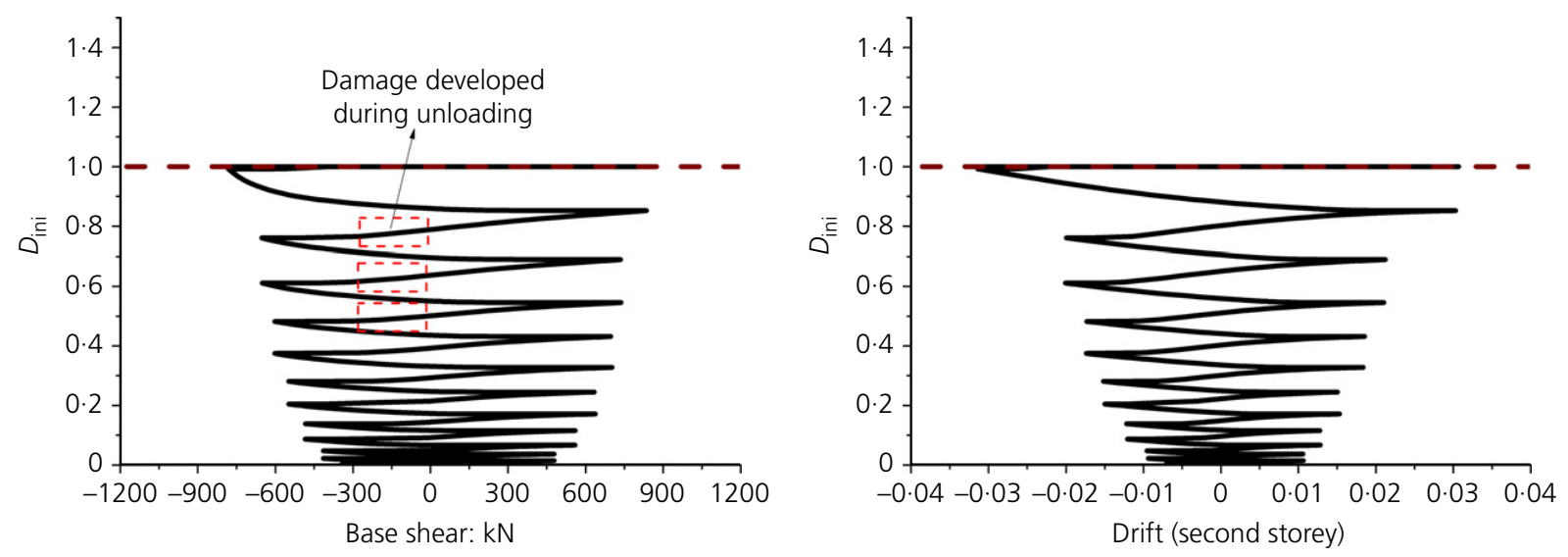

Figure 10. Damage evolution at cracking spot $A$

More importantly, it can be seen that $D_{\text {ini }}$ also increases during unloading; this is due to the fact that the restoring force of HSS members would lead to the yielding of EDBs in the unloading half cycle.

Considering that the motive of implementing EDBs in HSS frames is to provide stable energy dissipation under a ground motion or even a sequence of repeated ground motions, crack initiation of the EDBs is here taken as the limit state.

When applying the damage index for performance evaluation of a structure, the loading history of EDBs should be obtained first. In this regard, when performing an evaluation of EDBs, NL-RHA is needed first.

\subsubsection{Damage-control seismic evaluation procedure}

Based on the critical issues discussed above, it can be concluded that evaluating the damage-control behaviour of the system requires quantification of the performance of HSS members and EDBs simultaneously. In this regard, both the global response of a structure subjected to ground motions and the localised damage evolution in the EDBs should be explicitly assessed in practical design. However, the widely used design and evaluation procedures are still unable to comprehensively account for these issues, and running NL-RHA on detailed structural models in the evaluation procedure is time consuming. Therefore, a damage-control seismic evaluation procedure for HSS frames with EDBs was constructed, and the framework is given in Figure 11. In general, the entire procedure is composed of two modules. Specifically, module A can be used to quantify the performance of HSS members considering the potential inelastic behaviour, and module B is designated for the EDB performance evaluation with a focus on fracture identification. Essentially, the procedure starts with a non-linear static analysis to evaluate performance of HSS members first, corresponding to the first requirement discussed in Section 3.2. Since the second requirement is subordinate to the first, the application of module B should be based on the evaluation results of the performance of the HSS members. In module A, ground motions that lead to intersections of demand curves and capacity curves (Figure 8) approaching the damage-control threshold can be regarded as the most dangerous, since these ground motions would lead to relatively significant peak inelastic deformation of the EDBs, contributing to a drastic increase in the damage index, as indicated in Figure 10. They can thus be used as excitations for module B. In cases where the energy dissipation of the EDBs can be ensured to be redundant (application of specialised material after validation) or the cumulative effect is insignificant, only module $\mathrm{A}$ is required. Therefore, the procedure provides sufficient flexibility in practice.

\section{Application of the proposed procedure in damage-control evaluation}

To illustrate the application of the proposed procedure, a sixstorey HSS frame of EDBs was designed using the Chinese seismic code (CMC, 2010); the loading conditions used were the same as given in Section 2. Information about the design sections of the beams and columns is given in Figure 12(a). As a prototype structure, the EDBs were arranged in external bays. The HSS frame was designed with steel with a yield stress of $460 \mathrm{MPa}$. The beams in the EDB were designed with mild carbon steel with a yield stress of $235 \mathrm{MPa}$, and the reduced beam section (RBS) detail was considered to further enlarge the deformation range of the damage-control stage. The design of the RBS followed the Chinese seismic code (CMC, 2010) and AISC recommendations (AISC, 2010b). The plastic strength of the weakest section is also given in Figure 12(a).

Two models were developed (with Abaqus), considering evaluation module A or module B. Specifically, the model for module A was established based on beam elements (B31). For simplification, the connections were considered to be rigid in the model. To realise the RBS detail in the B31 elements 


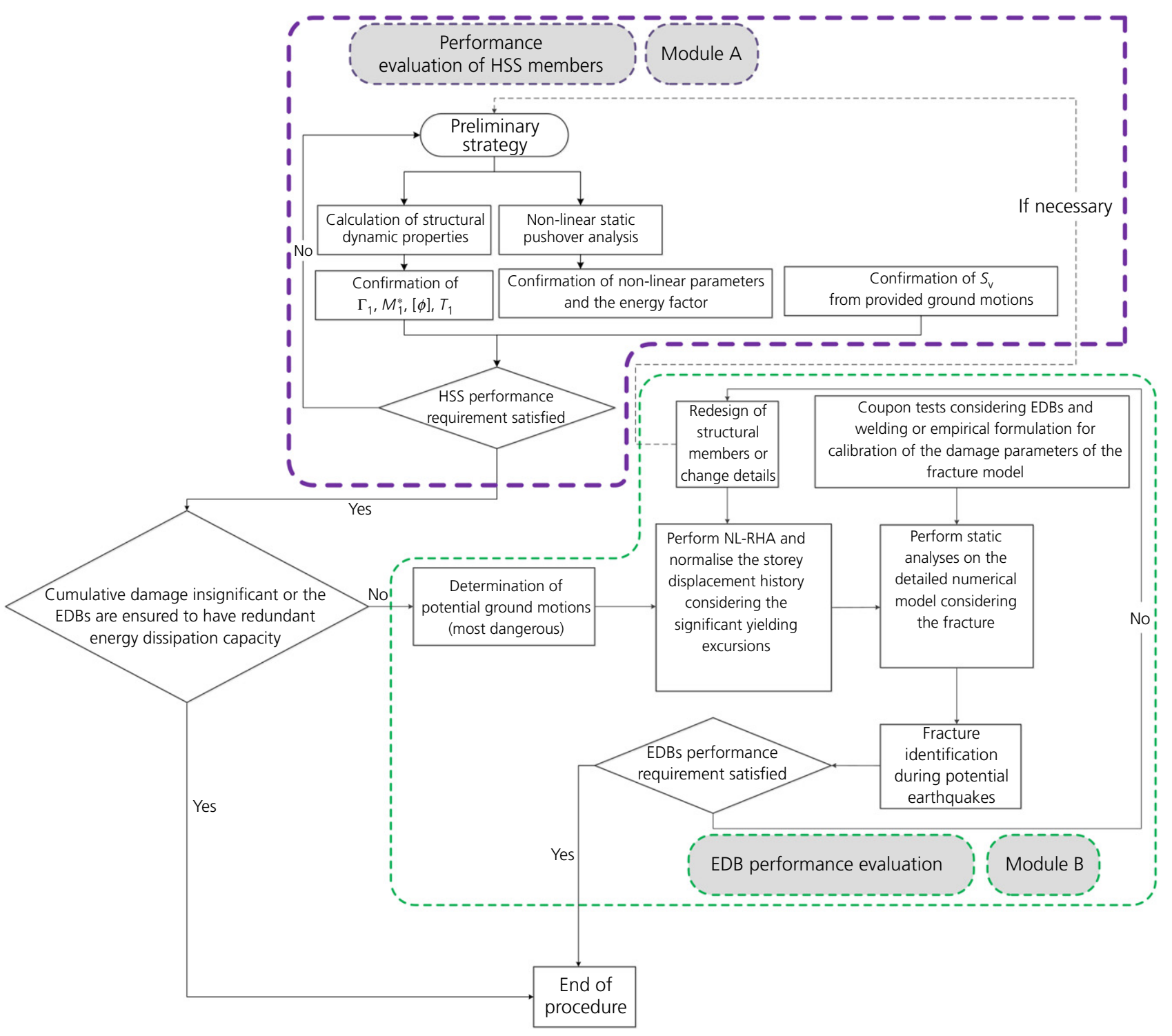

Figure 11. Flow chart of the proposed damage-control evaluation procedure

model, the yield stress of elements at the RBS location was reduced. The model for module $\mathrm{B}$ was established considering both beam elements and shell elements (S4R) (Figure 12(b)) to simulate fracture in the EDBs. The connection between the beam elements and shell elements was realised by means of kinematic coupling constraint. Thus, the loading history obtained from the NL-RHA based on the B31 model can be applied to the multi-scale model for module $\mathrm{B}$. The vibration properties of the two models were compared to ensure that they would have almost identical non-linear dynamic responses when subjected to an earthquake (Table 1). In the model for module A, Rayleigh damping of $5 \%$ was considered for the first two vibration modes. For both models, the material property was assigned based on the coupon test described in Section 3.3.2. In particular, the combined hysteretic law was considered for both the HSS members and the beams in the EBDs, and the fracture model was implemented in EDBs of shell elements. The mass was considered by the node mass distribution at floors. For the purposes of demonstration, a ground motion ensemble considering the stiff soil of Los Angeles (LA01-LA20) (Shome et al., 1998) was assumed as potential earthquakes. The acceleration spectra of these ground motions with an elastic damping ratio of $5 \%$ are presented in Figure 12(c).

The procedure was as follows.

Step 1. The vibration properties considering the fundamental mode of the prototype structure were calculated and the results are given in Table 1 . Good agreement 


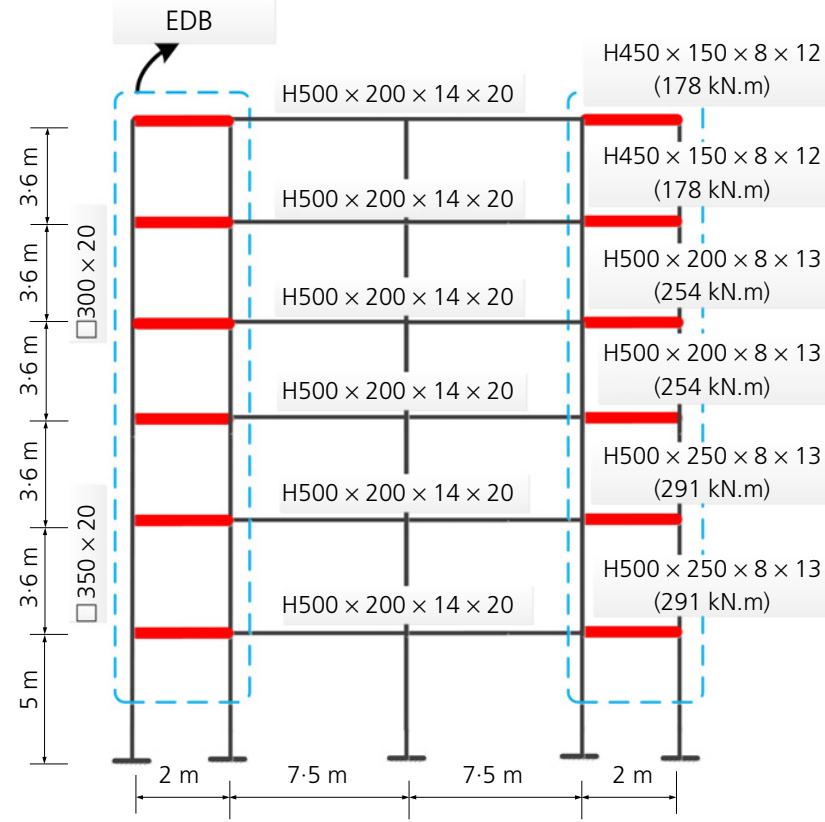

(a)

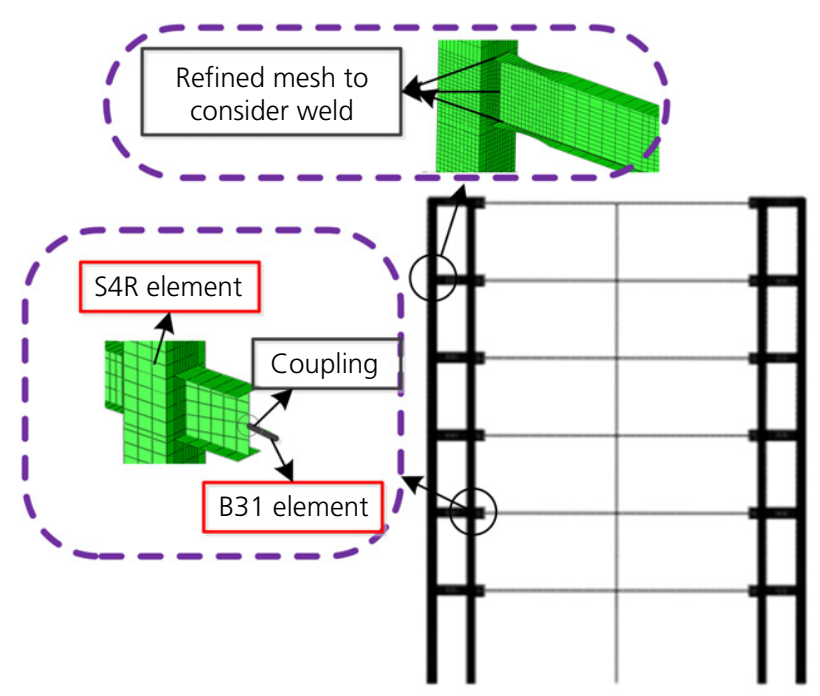

(b)

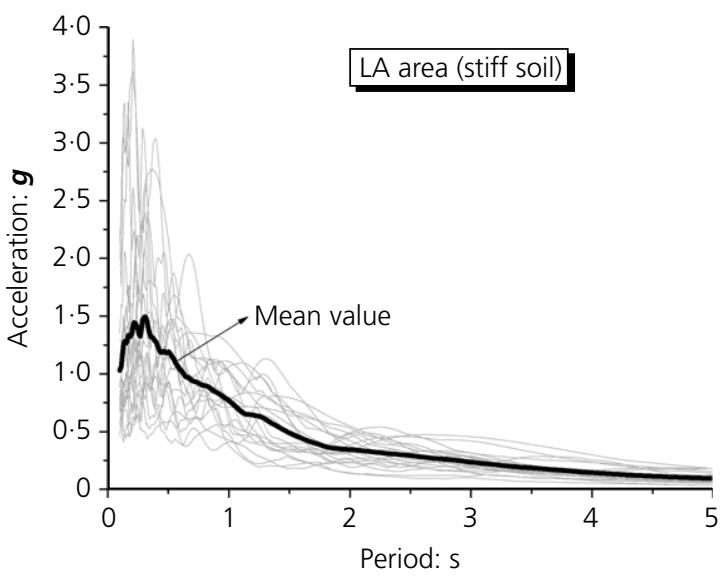

(c)

Figure 12. (a) Structural arrangement of the prototype structure. (b) Multi-scale model for module B in the procedure. (c) Ground motion acceleration spectra. $\square$, box section

Table 1. Dynamic properties of the prototype structure (six-storey HSS steel frame with EDBs)

\begin{tabular}{|lcc|}
\hline Property & $\begin{array}{c}\text { Beam model: } \\
\text { first mode }\end{array}$ & $\begin{array}{c}\text { Multi-scale model: } \\
\text { first mode }\end{array}$ \\
\hline Period: $s$ & 1.35 & 1.40 \\
Modal effective mass: $t$ & 471.3 & 467.2 \\
Modal participation factor & 1.29 & 1.29 \\
\hline
\end{tabular}

between the beam model and the multi-scale model with beam and shell elements verifies the rationality of the modelling process.
Step 2. After pushover analysis considering lateral load in proportion to the fundamental mode shape (applied to model with beam elements), the pushover curve can be obtained (Figure 13(a)). The shape of the DCC is confirmed.

Step 3. The corresponding $\gamma$ values considering the fundamental vibration mode associated with different sequence factors are plotted in Figure 14. Computation of this index is based on the self-developed algorithm BTESPEC (Ke et al., 2015), following the flow chart given in Figure 7(b). In addition, to clarify the effect of the DCC, perfectly elasto-plastic systems for an identical elastic 
Structures and Buildings

Volume 170 Issue SB9
Damage-control evaluation of high-strength steel frames with energy

dissipation bays

$\mathrm{Ke}$, Chen and Jia

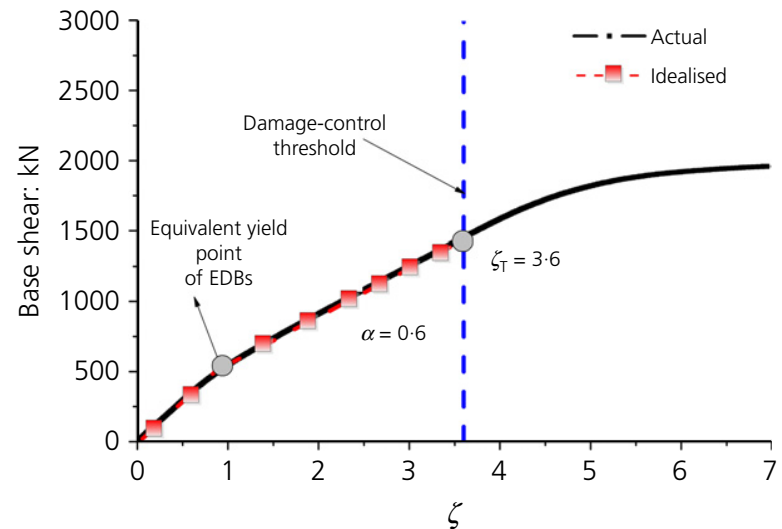

(a)

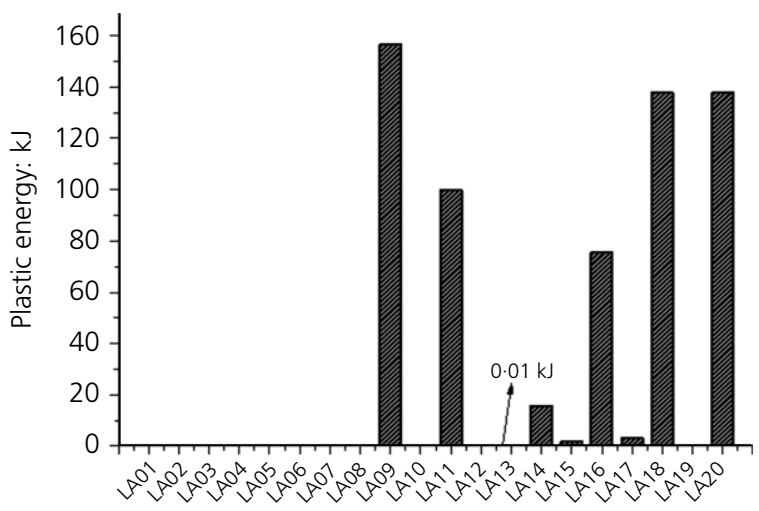

(c)

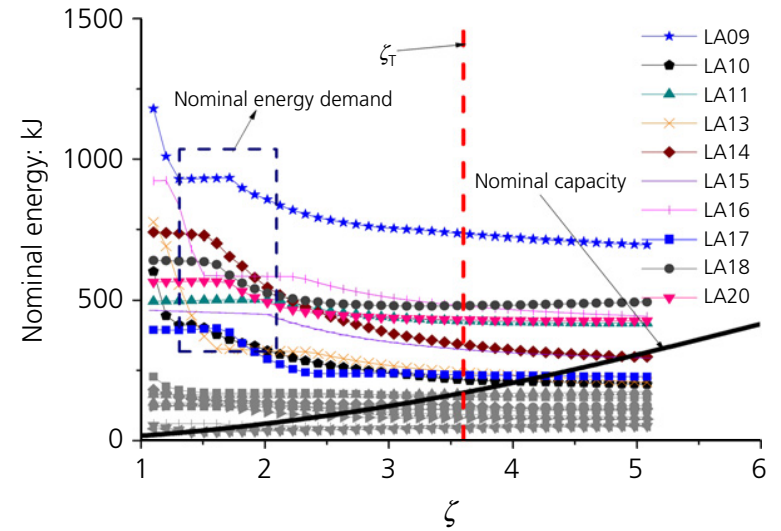

(b)

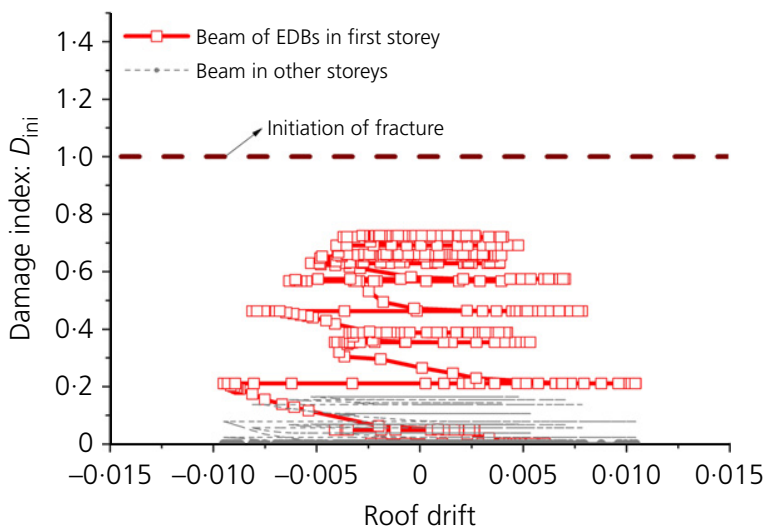

(d)

Figure 13. Results of evaluation procedure regarding the prototype structure: (a) pushover curve and idealisation; (b) module A in the procedure, based on energy balance concept; (c) plastic energy dissipation of HSS members extracted from NL-RHA; (d) maximum damage index history (LA01)
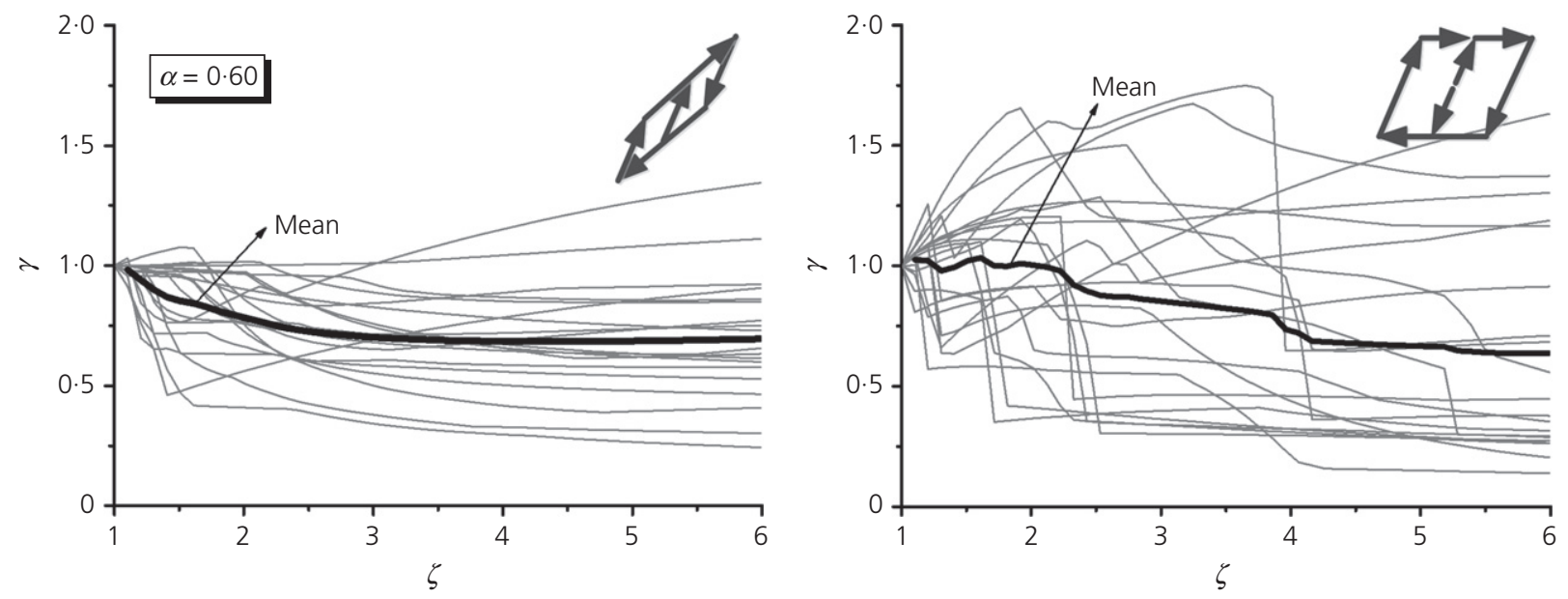

Figure 14. Energy factor considering different hysteretic models 
period were analysed. The clear difference induced by the different models validates the necessity of explicit consideration of the structural non-linear feature when combining HSS members with EDBs.

Step 4. A performance evaluation of the HSS members based on module A was performed; the results are shown in Figure 13(b). According to these results, it is predicted that there will be inelastic deformation in the HSS members in cases of LA09, LA10, LA11, LA13, LA14, LA15, LA16, LA17, LA18 and LA20 since the intersection points of the nominal capacity curve and the demand curves are above the damage-control threshold. To validate accuracy of the prediction, the plastic energy of the HSS members during ground motions computed by the NL-RHA is presented in Figure 13(c). The satisfactory accuracy of the prediction considering the damage in HSS members during ground motions demonstrates the rationality of module $\mathrm{A}$.

Step 5. For cases in which the structure sustains damage in the EDBs without inelastic damage to the HSS members, module B regarding fracture identification can be conducted with information of the ground motions and the results extracted from the NL-RHA. The results of module A can provide an instructive reference for the most dangerous earthquakes that would induce fracture. Specifically, it was observed that the interaction points of ground motions LA01, LA02 and LA03 approach the damage-control threshold, indicating that the EDBs would also have to experience significant inelastic deformation. In this respect, they can be used as excitations for module B. As an example, LA01 is considered in this step. Specifically, after performing the NL-RHA based on the model with beam elements, the corresponding displacement history is then applied in the multi-scale model for module B by a static analysis. The maximum damage index $\left(D_{\text {ini }}\right)$ response is then obtained (Figure 13(d)). Thus, there would be no fracture under this ground motion. However, it should be noted that ground motion LA01 corresponds to the design-based seismic hazard level. In this respect, the behaviour of the system subjected to more intense earthquakes should be critically assessed since damage to EDBs has already become significant under a design-based ground motion.

\section{Conclusions}

A seismic evaluation procedure regarding an innovative highstrength steel (HSS) structure (HSS frame with energy dissipation bays (EDBs)) has been proposed. With a focus on damage-control behaviour, rational requirements regarding the combination of HSS members and EDBs were clarified and an evaluation procedure was proposed in which a performance evaluation of the HSS members and fracture identification in the EDBs are simultaneously employed. Compared with direct application of non-linear response history analysis (NL-RHA) considering the entire structure under a group of ground motions, which is computationally consuming, the proposed procedure is more efficient. The procedure was applied to a prototype structure and its rationality was validated. The main findings can be summarised as follows.

- Cyclic testing of a large-scale specimen indicated that a combination of HSS frames with EDBs is an effective way of realising damage-control behaviour. A damage-control core, quantified by a bilinear model with significant postyielding stiffness, can be extracted.

- The seismic performance of the HSS can be reasonably evaluated based on an energy balance concept, and can be used to simplify or optimise the design of HSS members under provided ground motions. A comparison with conventional models indicated that the hysteretic feature variation induced by the combination of HSS members and EDBs would have a significant influence on the structural energy balance.

- The damage index extracted from the micromechanicsbased fracture model can be used to identify the potential fracture of EDBs conservatively. However, the case study indicated that, for a code-designed structure subjected to a ground motion in the design-based hazard level, the damage index might be significant. The proposed procedure just puts forth a solution for identifying the potential fracture of EDBs under a provided ground motion.

- By following module $\mathrm{A}$ in the damage-control evaluation procedure, the performance of HSS frames under ground motions can be evaluated by performing non-linear static analyses. Potential earthquakes that would trigger fracture of the EDBs can also be targeted.

- The application of module B in the damage-control evaluation procedure can identify fracture occurrence associated with loading history of EDBs subjected to the targeted ground motions obtained in module A.

- The results of the case study showed that the combination of module A and module B in a stepwise procedure can effectively account for the performance of HSS frames and EDBs simultaneously. Compared with running NL-RHA on a detailed structural model subjected to a group of ground motions, computational effort is greatly reduced, and irrational design of HSS members and EDBs can be reasonably detected.

\section{Acknowledgements}

This research is supported by the National Science Foundation of China (grants 51578403 and 51508401) and the fundamental Research Funding of the China Ministry of Science and Technology (SLDRCE14-A-03). 


\section{REFERENCES}

AISC (American Institute for Steel Construction) (2010b) ANSI/AISC 358-10: Prequalified connections for special and intermediate steel moment frames for seismic applications. AISC, Chicago, IL, USA.

AISC (2010a) ANSI/AISC 341-10: Seismic provisions for structural steel buildings. AISC, Chicago, IL, USA.

Bjorhovde R (2004) Development and use of high performance steel. Journal of Constructional Steel Research 60(3-5): 393-400.

Chey M, Chase JG, Mander JB and Carr AJ (2015) Aseismic smart building isolation systems under multi-level earthquake excitations: part II, energy-dissipation and damage reduction. Frontiers of Structural and Civil Engineering 9(3): 297-306.

Chopra AK and Chintanapakdee C (2004) Inelastic deformation ratios for design and evaluation of structures: single-degree-of-freedom bilinear systems. Journal of Structural Engineering ASCE 130(9): 1309-1319.

CMC (China Ministry of Construction) (2010) GB 50011-2010: Code for seismic design of buildings. CMC, Beijing, China.

Dubina D, Stratan A and Dinu F (2008) Dual high-strength steel eccentrically braced frames with removable links. Earthquake Engineering and Structural Dynamics 37(15): 1703-1720.

Ellobody E (2012) Behaviour of normal and high-strength castellated steel beams. Proceedings of the Institution of Civil Engineers Structures and Buildings 165(10): 529-542, http://dx.doi.org/ 10.1680/stbu. 10.00054

Fang C, Yam MCH, Lam ACC and Xie LK (2014) Cyclic performance of extended end-plate connections equipped with shape memory alloy bolts. Journal of Constructional Steel Research 94: 122-136.

Green PS, Sause R and Ricles JM (2002) Strength and ductility of HPS flexural members. Journal of Constructional Steel Research 58(5-8): 907-941.

Hatzigeorgiou GD and Beskos DE (2009) Inelastic displacement ratios for SDOF structures subjected to repeated earthquakes. Engineering Structures 31(11): 2744-2755.

Jia LJ and Kuwamura H (2014) Ductile fracture simulation of structural steels under monotonic tension. Journal of Structural Engineering ASCE 140(5): 472-482.

Jia LJ and Kuwamura H (2015) Ductile fracture model for structural steel under cyclic large strain loading. Journal of Constructional Steel Research 106: 110-121.

Jia LJ, Kato T and Ge H (2014) Ductile cracking simulation of butt weld in steel structures under monotonic tension. Proceedings of the 13th International Symposium on Structural Engineering, Hefei, China, pp. 1778-1786.

Jia LJ, Ikai T, Shinohara K and Ge H (2016) Ductile crack initiation and propagation of structural steels under cyclic combined shear and normal stress loading. Construction and Building Materials 112: 69-83.

Kalkan E and Kunnath SK (2007) Assessment of current nonlinear static procedures for seismic evaluation of buildings. Engineering Structures 29(3): 305-316.

Ke K and Chen Y (2014) Energy-based damage-control design of steel frames with steel slit walls. Structural Engineering and Mechanics 52(6): 1157-1176.

Ke K and Chen Y (2016) Seismic performance of MRFs with high strength steel main frames and EDBs. Journal of Constructional Steel Research 126: 214-228.

Ke K, Ke S and Chuan G (2015) The energy factor of systems considering multiple yielding stages during ground motions. Soil Dynamics and Earthquake Engineering 71: 42-48.

Lagaros ND and Fragiadakis M (2011) Evaluation of ASCE-41, ATC-40 and N2 static pushover methods based on optimally designed buildings. Soil Dynamics and Earthquake Engineering 31(1): 77-90.

Leelataviwat S, Saewon W and Goel SC (2009) Application of energy balance concept in seismic evaluation of structures. Journal of Structural Engineering ASCE 135(2): 113-121.

Miki C, Homma K and Tominaga T (2002) High strength and high performance steels and their use in bridge structures. Journal of Constructional Steel Research 58(1): 3-20.

Nakashima M, Saburi K and Tsuji B (1996) Energy input and dissipation behaviour of structures with hysteretic dampers. Earthquake Engineering and Structural Dynamics 25(5): 483-496.

Sahoo DR and Chao S (2010) Performance-based plastic design method for buckling-restrained braced frames. Engineering Structures 32(9): 2950-2958.

Sause R and Fahnestock L (2001) Strength and ductility of HPS-100W I-girders in negative flexure. Journal of Bridge Engineering 6(5): 316-323.

Shome N, Cornell CA, Bazzurro P and Carballo JE (1998) Earthquakes, records, and nonlinear responses. Earthquake Spectra 14(3): 469-500.

Tenchini A, D'Aniello M, Rebelo C et al. (2014) Seismic performance of dual-steel moment resisting frames. Journal of Constructional Steel Research 101: 437-454.

Wada A, Connor JJ, Kawai H, Iwata M and Watanabe A (1992) Damage tolerant structure. Proceedings of the 5th US-Japan Workshop on the Improvement of Building Structural Design and Construction Practice, San Diego, CA, USA, pp. 27-39.

Wongpakdee N, Leelataviwat S, Goel SC and Liao WC (2014) Performance-based design and collapse evaluation of buckling restrained knee braced truss moment frames. Engineering Structures 60: 23-31.

\section{How can you contribute?}

To discuss this paper, please email up to 500 words to the editor at journals@ice.org.uk. Your contribution will be forwarded to the author(s) for a reply and, if considered appropriate by the editorial board, it will be published as discussion in a future issue of the journal.

Proceedings journals rely entirely on contributions from the civil engineering profession (and allied disciplines). Information about how to submit your paper online is available at www.icevirtuallibrary.com/page/authors, where you will also find detailed author guidelines. 